\title{
Discrepant expression and prognostic role of epidermal growth factor receptor and icotinib radiosensitization for nasopharyngeal carcinoma
}

\section{Bo Wu}

Taizhou Central Hospital(Taizhou University Hospital)

\section{Hua-cai Xiong}

Lingbo Medical Center Lihuili Hospital

\section{Yong Wang}

Taizhou Central Hospital(Taizhou University Hospital)

Hong-sheng Lu

Taizhou Central Hospital(Taizhou University Hospital)

\section{Qi Chen}

Taizhou Central Hospital(Taizhou University Hospital)

\section{Shen-peng Ying ( $\sim$ 418145386@qq.com )}

\section{Research}

Keywords: Nasopharyngeal carcinoma, epidermal growth factor receptor, icotinib, radioresistance, prognosis

Posted Date: April 6th, 2020

DOI: https://doi.org/10.21203/rs.3.rs-20637/v1

License: (a) This work is licensed under a Creative Commons Attribution 4.0 International License. Read Full License 


\section{Abstract}

Background: Epidermal growth factor receptor (EGFR) expression was observed in many tumors. Icotinib (IH), an EGFR tyrosine kinase inhibitor, could enhance the radiosensitivity, but few studies have focused on nasopharyngeal carcinoma (NPC).

Materials and Methods : One hundred fifteen NPC lesions and 30 nasopharyngitis lesions were enrolled for EGFR expression evaluation with immunohistochemical staining. The correlation of EGFR expression and clinical parameters was analyzed. Survival analysis was calculated using univariate and multivariate analysis. A radioresistant NPC cell line, CNE-2R, was established with a gradient irradiation schedule of $60 \mathrm{~Gy}$ from CNE-2. Cell viability of $\mathrm{CNE}-2 / 2 \mathrm{R}$ was detected using microculture tetrazolium assay and colony-forming assay. The IH radiosensitization effect and EGFR expression were also evaluated in CNE-2/2R.

Results: High EGFR expression was more frequently detected in NPC lesions (73/115) than chronic nasopharyngitis lesions $(5 / 30, p=0.000)$. EGFR expression was correlated with tumor stage $(p=0.000)$ and tumor-node-metastasis (TNM) stage ( $p=0.006)$. EGFR expression was an independent prognostic factor of disease-free survival $(p=0.047)$ and overall survival ( $p=0.016$ ). The optical density value of CNE-2R was higher than CNE-2 on days $1,2,4$, and 6 after radiation of $4 \mathrm{~Gy}(\mathrm{p}<0.005)$. CNE-2 colony numbers clearly decreased compared with CNE- $2 \mathrm{R}(\mathrm{p}<0.05)$, and $\mathrm{IH}$ enhanced the radiosensitizing effect of CNE-2R with an apparently lower survival fraction $(1.414$ times, $p<0.05)$. Higher EGFR expression was observed in CNE-2R cells and decreased accordingly when exposed to $\mathrm{IH}$.

Conclusion: High EGFR expression was more frequently detected as a poor prognostic factor in NPC patients. Higher radioresistance and EGFR expression were observed in CNE-2R, and IH could reduce it. These results provided a new theoretical basis for clinical application of icotinib radiosensitization in NPC radiotherapy.

\section{Introduction}

Nasopharyngeal carcinoma (NPC) is a common malignant tumor with regional distribution in southern China with an annual incidence of 3.0 per 100,000 persons[1]. Radiotherapy with or without chemotherapy is the predominant treatment modality for NPC, especially local advanced NPC. It is well-known that distant metastasis and local failure contribute largely to poor outcome[2,3]. Residual irradiated NPC cells with high radioresistance are the most common cause. In addition, chemotherapy drugs are regarded as radiosensitizers in the concurrent chemoradiotherapy of local advanced NPC[4, 5]. However, severe therapeutic side effects, including myelosuppression and mucositis lead to reduced treatment tolerance and quality of life[6]. Thus, it is urgent to explore effective therapeutic strategies for increasing radiosensibility with fewer side effects.

Epidermal growth factor receptor (EGFR) is a transmembrane glycoprotein that belongs to the ErbB receptor tyrosine kinase family, which enhances cancer cell proliferation, differentiation, metastasis, and angiogenesis[7]. EGFR overexpression has been demonstrated in NPC, which involves chemo-/radioresistance, malignant progression, and poor survival, making it possible to block the EGFR signal pathway to improve the radiosensitivity[8, 9]. EGFR inhibitors include monoclonal antibodies and small molecule tyrosine kinase inhibitors. For the former, Huang et al. demonstrated that concurrent administration of nimotuzumab and celecoxib cooperatively enhanced the cytotoxicity and radiosensitivity of NPC cells (CNE-2) in vitro[10]. Clinical studies have shown that cetuximab or nimotuzumab, combined with radiotherapy can enhance the efficacy of radiotherapy with a better safety profile[11-13].

Icotinib hydrochloride $(\mathrm{IH})$, a small molecule inhibitor of EGFR, has shown radiosensibility in several malignant tumors. Zhang et al. found that pretreatment with IH reduced clonogenic survival, inhibited EGFR activation, and 
increased radiation-induced apoptosis of lung cancer cells[14]. Similar results were also observed in colorectal cancer and cervical cancer cells[15, 16]. However, very little is known about the radiosensitization of IH on NPC. In our previous study, IH (125 mg/day) plus intensity-modulated radiation therapy (IMRT) in patients with locally advanced NPC had an acceptable safety profile and was well tolerated[17]. Hence, we check EGFR expression and its correlations with clinical pathological features in NPC patients, and then explore IH radiosensitization efficacy to NPC cells.

\section{Materials And Methods}

\subsection{Tissue samples}

According to the Helsinki Declaration, this study was approved by the Institutional Review Board committee of Taizhou Central Hospital (Taizhou University Hospital) and Taizhou Hospital of Zhejiang Province. All the enrolled patients signed an informed consent form for the potential use of biopsy specimens for scientific research. To protect their privacy, only de-identified patient data were used.

On hundred fifteen primary NPC paraffin-embedded specimens were collected from the two hospital tissue banks between January 2011 and October 2017 with the approval of the Ethics Committee. Chronic nasopharyngitis lesions $(n=30)$ were collected between August 2017 and October 2017. All the patients were pathologically diagnosed with immunohistochemistry, and NPC patients with distant metastasis were excluded at the time of diagnosis. According to the 7th edition of the American Joint Committee on Cancer staging system, tumor-node-metastasis (TNM) staging score was determined. All the patients received standard treatment with radiotherapy, chemotherapy, or chemoradiotherapy. There was also no another malignant disease history for the selected patients. The median age of 115 patients was 54 years (ranging from 30 to 82 years), and other detailed characteristics are summarized in Table 1. The average follow-up was $53.7 \pm 25.1$ months (range: 10.6-99 months). 
Table 1

Correlation of EGFR expression in NPC lesions with clinicopathological parameters.

\begin{tabular}{|c|c|c|c|c|}
\hline \multirow[t]{2}{*}{ Clinical features } & \multirow[t]{2}{*}{ Case numbers } & \multicolumn{2}{|c|}{ EGFR expression } & \multirow[t]{2}{*}{ p-value } \\
\hline & & Low(42) & High(73) & \\
\hline \multicolumn{5}{|l|}{ Gender } \\
\hline Male & 80 & 30 & 50 & 0.742 \\
\hline Female & 35 & 12 & 23 & \\
\hline \multicolumn{5}{|l|}{ Age (years) } \\
\hline$\leq 54$ & 63 & 18 & 43 & 0.510 \\
\hline$>54$ & 52 & 24 & 28 & \\
\hline \multicolumn{5}{|c|}{ Tumor differentiation } \\
\hline Keratinizing & 15 & 6 & 9 & 0.764 \\
\hline Non-Keratinizing & 100 & 36 & 64 & \\
\hline \multicolumn{5}{|l|}{ Tumor stage } \\
\hline $\mathrm{T} 1+\mathrm{T} 2$ & 74 & 36 & 38 & 0.000 \\
\hline $\mathrm{T} 3+\mathrm{T} 4$ & 41 & 6 & 35 & \\
\hline \multicolumn{5}{|c|}{ Lymph node status } \\
\hline NO & 56 & 26 & 30 & 0.328 \\
\hline N1-3 & 59 & 16 & 43 & \\
\hline \multicolumn{5}{|l|}{ TNM stage } \\
\hline$I+I I$ & 39 & 21 & 18 & 0.006 \\
\hline $\mathrm{III}+\mathrm{IV}$ & 76 & 21 & 55 & \\
\hline
\end{tabular}

\subsection{Immunohistochemical staining and score for EGFR}

Paraffin-embedded slides of $4 \mu \mathrm{m}$ were dewaxed in xylene and rehydrated through a graded series of ethanol. Antigen retrieval was performed by boiling the slides with citrate buffer $(\mathrm{pH}=6)$ at $120^{\circ} \mathrm{C}$ for $5 \mathrm{~min}$, then blocked by normal goat serum. Internal peroxidase activity was blocked using a $3 \%$ hydrogen peroxide solution at room temperature for $15 \mathrm{~min}$. After that, the samples were incubated with antibodies against EGFR (18986-1-AP, Proteintech Group, Wuhan, China) at $4{ }^{\circ} \mathrm{C}$ overnight. After washing with $0.01 \mathrm{M}$ of phosphate-buffered saline (PBS) solution, the samples were incubated with labeled goat anti-rabbit secondary antibody (SA00001-2, Proteintech Group, Wuhan, China) for 60 min at $37^{\circ} \mathrm{C}$. Following washing with PBS again, the samples were stained with diaminobenzidine solution, counterstained with hematoxylin, and mounted with glycerol gelatin.

EGFR expression was semi-qualitatively assessed by two pathologists according to positive staining intensity and percentage in cell membrane with or without cytoplasm. EGFR expression was graded as follows: negative; >5-25\%, 
$(1+) ;>25-50 \%,(2+)$; and > 50\%, (3+). Furthermore, negative and $1+$ grades were classified as low EGFR expression, and $2+$ and $3+$ grades were classified as high EGFR expression.

\subsection{Cell lines and cultures}

Human NPC cell line CNE-2 was obtained from American Type Culture Collection (ATCC, Manassas, VA, USA), Cells were maintained in Roswell Park Memorial Institute (RPMI-1640, Invitrogen Life Technologies, Carlsbad, CA, USA) supplemented with 10\% fetal bovine serum (Hyclone, Logan, UT, USA) and 1\% penicillin/streptomycin, and cultured in a humidified incubator in $37^{\circ} \mathrm{C} / 5 \% \mathrm{CO}_{2} . \mathrm{IH}$ was purchased from Zhejiang Beta Pharma, Ltd. (Hangzhou, China) and dissolved in $100 \%$ dimethyl sulfoxide (DMSO) to a final concentration of $40 \mathrm{mg} / \mathrm{ml}$ and stored at $-20^{\circ} \mathrm{C}$.

\subsection{Generation of radioresistant subclone}

When CNE-2 cells reached approximately $60 \%$ confluence, the gradient irradiation schedule was initiated: The flask surface was covered by tissue equivalent filler with a thickness of $1.5 \mathrm{~cm}$ and then subjected to 2 Gy using Siemens clinical linear accelerator (Primus H, 6MV-X, dosage rate of $200 \mathrm{cGy} / \mathrm{min}$, source skin distance $100 \mathrm{~cm}$, and irradiation field of $10 * 10$ centimeter). Following radiation exposure, cells were further cultured in a new flask. When they reached $60 \%$ confluence again, cells were then irradiated to $2 \mathrm{~Gy}$ a second time. These procedures were repeated three times with a gradient model of 2, 4, 6, and 8 Gy to the total dose of $60 \mathrm{~Gy}$ in 12 months, and the surviving cells were cultured and named CNE-2R. Another flask of CNE-2 cells was cultured synchronously as a control cell line with no radiation exposure.

\subsection{Microculture tetrazolium (MTT) assay}

CNE-2/2R cells in the exponential phase were seeded and incubated overnight in 96-well micro-titer plates at a density of 5,000 cells/well with a volume of $100 \mathrm{ul} /$ well. CNE-2/2R cells were irradiated with the dose of 4 Gy according to the above irradiation scheme. MTT assay was performed to test optical density (OD) value on days 1, 2, 4, and 6 after irradiation. Briefly, CNE-2/2R cells were treated with $20 \mu \mathrm{l} /$ well of 3-(4, 5-diethyl-2-thiazolyl)-2, 5-diphenyltetrazolium bromide $(5 \mathrm{mg} / \mathrm{ml})$ for $4 \mathrm{~h}$ at $37^{\circ} \mathrm{C}$, resulting in the generation of formazan crystals. After aspirating the medium, DMSO (150 $\mathrm{\mu l} /$ well) was added to dissolve the formazan for $10 \mathrm{~min}$, and then OD value was measured in a microplate reader (Safe Heart, SHE 3000) at a wavelength of $490 \mathrm{~nm}$. Each group had three repeated wells on different days.

CNE-2 cells in the exponential phase were seeded in 96-well microtiter plates at a density of 10,000 cells/well and incubated overnight. CNE-2 cells were then treated by $\mathrm{IH}$ with different final concentrations $(0.013,0.025,0.05,0.1,0.2$, and $0.4 \mathrm{mg} / \mathrm{ml}$ ) in a total volume of $100 \mathrm{ul} /$ well. After $24 \mathrm{~h}$ of $\mathrm{IH}$ addition, MTT assay was performed, and the percentage inhibition rate was calculated as: (1 - OD value of experimental group/control group OD) x100\%. The IC20 (20\% inhibitory concentration) was selected as the subsequent experimental concentration.

\subsection{Colony-forming assay}

CNE-2/2R cells in the exponential phase were seeded in 6-well plates with appropriate densities (300-3,000/well). Three cohorts were conducted: CNE-2, CNE-2R, and CNE-2R + IH. NPC cells were incubated in the medium containing IH (IC20 concentration) or DMSO for $24 \mathrm{~h}$. After substituting with complete growth medium, the plates were correspondingly irradiated with $0 \mathrm{~Gy}, 2 \mathrm{~Gy}, 4 \mathrm{~Gy}, 6 \mathrm{~Gy}, 8 \mathrm{~Gy}$, and $10 \mathrm{~Gy}$ depending on cell numbers and continuously incubated for approximately 10 to 14 days. The incubation ended until a macroscopic colony (> 50 cells per colony) appeared. Plates were subjected to Giemsa staining and counted under an inverted microscope. The plating efficiency (PE) was calculated as the fraction of colonies counted divided by the numbers of cells. The survival fraction (SF) was then calculated as colonies counted / (cells seeded x PE/100). Eventually, the data were fitted to a single hit 
multiple targets equation, which was expressed as SF = 1 - [1-exp (-D/D0)]^ N using GraphPad Prism 6.0 software. The cell survival curve was obtained, and radiosensitivity parameters (D0, Dq, N, SF2) were compared.

\subsection{Western Blot assay}

The CNE-2, CNE-2R, and CNE-2R + IH groups in the exponential phase were treated with or without IH for $24 \mathrm{~h}$. The medium containing $\mathrm{IH}$ or DMSO was substituted with complete growth medium, and then cells were irradiated with $4 \mathrm{~Gy}$. After $24 \mathrm{~h}$, the protein lysates of the three cell groups were harvested and centrifuged, and then the supernatants were collected. Protein was separated by $10 \%$ sodium dodecyl sulfate polyacrylamide gel electrophoresis (SDS-PAGE) and transferred to polyvinylidene difluoride (PVDF) membranes. After blocking with $5 \%$ protease-free bovine serum albumin for 1 hour, the membranes were incubated with EGFR antibody (18986-1-AP, Proteintech Group, Wuhan, China) overnight at $4^{\circ} \mathrm{C}$. Following washing with tris-buffered saline with Tween (TBST) three times, the membranes were continually incubated with secondary antibody labeled with horseradish peroxidase. The bands of EGFR were finally visualized. GAPDH was used as an internal control to balance equal loading.

\subsection{Statistical analysis}

Statistical analysis was performed with PASW Statistics V18.0 software. All quantitative data are represented as mean values $( \pm$ SEM), and statistical differences between groups were analyzed using the t-test. GraphPad Prism software V6.0 was used for graphing the data. The correlation between EGFR expression and clinical parameters was calculated with the Pearson's chi-squared $\left(\mathrm{x}^{2}\right)$ test. Survival analysis was conducted according to the Kaplan-Meier method and Cox proportional hazards regression analysis. $\mathrm{P}<0.05$ was considered to be significant.

\section{Results}

\subsection{EGFR expression of NPC lesions and chronic nasopharyngitis lesions}

Positive staining was observed in the membrane and cytoplasm region (Fig. 1). Overall, EGFR positive expression was observed in 96 of 115 (83.5\%) NPC lesions, which EGFR intensity in 20.0\% (23/115) was 1+, 49.6\% (57/115) was 2+, $13.9 \%$ (16/115) was 3+, respectively. As for chronic nasopharyngitis patients, there were 7 of $30(23.3 \%)$ lesions with EGFR positive expression, of which EGFR intensity in $6.7 \%(2 / 30)$ was $1+, 10.0 \%(3 / 30)$ was $2+$, and $6.7 \%(2 / 30)$ was $3+$, respectively. According to the grade definition, high and low levels of EGFR expression were noted in 73 (63.48\%) and 42 (36.52\%) NPC patients, 5 (16.7\%) and 25 (83.3\%) chronic nasopharyngitis patients, with a significant statistical difference $(p=0.000)$.

\subsection{Association of EGFR expression and clinical parameters in NPC patients}

The association between EGFR expression and clinical parameters of NPC patients was shown in Table 1. The results demonstrated that EGFR expression level in NPC lesions was significantly correlated with T stage $(p=0.000)$ and TNM stage $(p=0.006)$. No correlation was observed between EGFR expression and gender, age, tumor differentiation, and lymph node status.

\subsection{Association of EGFR expression and NPC patients' survival}

The 5-year disease-free survival (DFS) and overall survival (OS) rate in 115 NPC patients was $72.7 \%$ and $75.3 \%$, respectively. Patients with high EGFR expression had a poorer DFS $(62.6 \%$ and $87.1 \%, p=0.049)$ and 0 S $(69.2 \%$ and 
$87.9 \%, p=0.042$ ) than those with low expression (Table 2, Fig. 2). After adjusting for prognostic factors, univariate and multivariate Cox proportional regression analysis showed that EGFR expression (HR: 3.10; 95\% confidence interval (Cl) [1.02-9.44], $\mathrm{p}=0.047$ ) and TNM stage (HR: 3.31; 95\% Cl [1.06-10.31, $\mathrm{p}=0.039)$ were independent prognostic factors for DFS (Table 3). Similarly, EGFR expression (HR: 3.05; 95\% Cl [1.23-7.59], $p=0.016)$, age (HR: 3.16; 95\% Cl [1.37-7.31], $p=0.007)$ and TNM stage (HR: 3.16; 95\% Cl [1.17-8.52], $p=0.023)$ were found to be independent prognostic factors for OS.

Table 2

Cox proportional regression analysis of variables affecting disease free survival (DFS) and overall survival (OS) in NPC patients.

\begin{tabular}{|c|c|c|c|c|c|c|c|c|c|}
\hline \multirow[t]{3}{*}{ Variables } & \multirow[t]{3}{*}{ Subsets } & \multicolumn{4}{|c|}{ Disease free survival } & \multicolumn{4}{|c|}{ Overall survival } \\
\hline & & \multicolumn{2}{|c|}{ Univariate analysis } & \multicolumn{2}{|l|}{$\begin{array}{l}\text { Multivariate } \\
\text { analysis }\end{array}$} & \multicolumn{2}{|c|}{$\begin{array}{l}\text { Univariate } \\
\text { analysis }\end{array}$} & \multicolumn{2}{|c|}{$\begin{array}{l}\text { Multivariate } \\
\text { analysis }\end{array}$} \\
\hline & & $\begin{array}{l}\mathrm{HR}(95 \% \\
\mathrm{Cl})\end{array}$ & $\mathbf{p}$ & $\begin{array}{l}\mathrm{HR}(95 \% \\
\mathrm{Cl})\end{array}$ & p & $\begin{array}{l}\mathrm{HR} \\
(95 \% \\
\mathrm{Cl})\end{array}$ & $\mathbf{p}$ & $\begin{array}{l}\mathrm{HR} \\
(95 \% \\
\mathrm{Cl})\end{array}$ & $\mathbf{p}$ \\
\hline $\begin{array}{l}\text { EGFR } \\
\text { expression }\end{array}$ & $\begin{array}{l}\text { High VS } \\
\text { low }\end{array}$ & $\begin{array}{l}3.00(1.00- \\
8.98)\end{array}$ & 0.049 & $\begin{array}{l}3.10 \\
(1.02- \\
9.44)\end{array}$ & 0.047 & $\begin{array}{l}2.56 \\
(1.04- \\
6.31)\end{array}$ & 0.042 & $\begin{array}{l}3.05 \\
(1.23- \\
7.59)\end{array}$ & 0.016 \\
\hline Gender & $\begin{array}{l}\text { Male VS } \\
\text { female }\end{array}$ & $\begin{array}{l}0.51 \\
(0.21- \\
1.23)\end{array}$ & 0.134 & $\begin{array}{l}0.71 \\
(0.28- \\
1.79)\end{array}$ & 0.471 & $\begin{array}{l}1.09 \\
(0.48- \\
2.49)\end{array}$ & 0.830 & $\begin{array}{l}1.30 \\
(0.56- \\
3.02)\end{array}$ & 0.540 \\
\hline Age (years) & $\begin{array}{l}\leq 54 \mathrm{VS}> \\
54\end{array}$ & $\begin{array}{l}1.00 \\
(0.41- \\
2.41)\end{array}$ & 0.999 & $\begin{array}{l}1.03 \\
(0.40- \\
2.64)\end{array}$ & 0.947 & $\begin{array}{l}3.09 \\
(1.36- \\
7.02)\end{array}$ & 0.007 & $\begin{array}{l}3.16 \\
(1.37- \\
7.31)\end{array}$ & 0.007 \\
\hline $\begin{array}{l}\text { Tumour } \\
\text { differentiation }\end{array}$ & $\begin{array}{l}\text { Keratinized } \\
\text { VS non- } \\
\text { keratinized }\end{array}$ & $\begin{array}{l}0.50(0.18- \\
1.37)\end{array}$ & 0.177 & $\begin{array}{l}0.38 \\
(0.13- \\
1.09)\end{array}$ & 0.072 & $\begin{array}{l}0.70 \\
(0.27- \\
1.85)\end{array}$ & 0.471 & $\begin{array}{l}0.72 \\
(0.27- \\
1.94)\end{array}$ & 0.517 \\
\hline TNM stage & $\begin{array}{l}(I+I I) V S \\
(I I I+I V)\end{array}$ & $\begin{array}{l}3.36 \\
(1.12- \\
10.07)\end{array}$ & 0.030 & $\begin{array}{l}3.31(1.06- \\
10.31)\end{array}$ & 0.039 & $\begin{array}{l}3.29 \\
(1.25- \\
8.67)\end{array}$ & 0.016 & $\begin{array}{l}3.16 \\
(1.17- \\
8.52)\end{array}$ & 0.023 \\
\hline
\end{tabular}


Table 3

The main parameters of cell survival curves of CNE-2 and CNE-2R treated irradiation with or without icotinib.

\begin{tabular}{|llll|}
\hline parameters & CNE-2 & CNE-2R + IH & CNE-2R \\
\hline D0 & 2.088 & 1.898 & 2.695 \\
\hline Dq & 1.995 & 1.466 & 3.487 \\
\hline $\mathrm{N}$ & 2.600 & 2.165 & 3.647 \\
\hline SF2 & 0.715 & 0.604 & 0.854 \\
SER & & 1.414 & \\
\hline
\end{tabular}

D0, mean lethal dose; Dq, quasi-threshold dose; N, extrapolation number; SF2, surviving fraction at 2 Gy; IH, Icotinib.

\subsection{Radiosensitivity differences between CNE-2/2R cells and IH radiosensitization efficacy on CNE-2R cells}

The CNE-2R cell line was generated by graded doses of irradiation. The morphology of CNE-2/2R cells were distinguished under an inverted microscope (Fig. 3A, 3B). CNE-2 cells grew in a multilateral manner, while the CNE-2R cells had a spindle or fusiform shape. CNE-2R cells exhibited an advantage in cell proliferation compared with CNE-2 cells. After radiation of $4 \mathrm{~Gy}$, the OD value of CNE-2R was higher than CNE-2 at day $1(0.510 \pm 0.0346,0.367 \pm 0.0351$, $p=0.007)$, day $2(1.070 \pm 0.151,0.623 \pm 0.031, p=0.007)$, day $4(1.157 \pm 0.227,0.713 \pm 0.091, p=0.035)$, and day 6 $(1.367 \pm 0.083,1.117 \pm 0.055, p=0.036)($ Fig. $3 C)$.

MTT assay was performed to detect the effect of IH on cell viability and IC20 value $(0.04 \mathrm{mg} / \mathrm{ml})$ was obtained for subsequent experiments (Fig. 3D). In clonogenic assay, the radiosensitivity difference between CNE-2/2R was obvious (Table 3 and Fig. 4A). In response to radiation, there was a dose-dependent reduction of clonogenic cell survival. CNE2 colony numbers decreased compared with CNE-2R $(p<0.05)$, and IH enhanced the radiosensitizing effect of CNE-2R with an apparently lower survival fraction $(1.414$ times, $p<0.05)$.

\subsection{EGFR expression profiles in CNE-2/2R cells.}

In RT-PCR assay, the EGFR expression level was 1.343 times higher in CNE-2R cells than CNE-2 cells $(p<0.05)$. In western blot assay, GAPDH was used as an internal control. Compared with CNE-2 cells, EGFR protein expression was higher in CNE-2R cells (Fig. 4B). When IH was added, EGFR expression was decreased accordingly. These results demonstrated that EGFR expression was higher in the radioresistant cell lines than the parental cell line and $\mathrm{IH}$ could reduce EGFR expression.

\section{Discussion}

Although NPC is sensitive to radiotherapy, local recurrence and distant metastasis remain the leading causes resulting in treatment failure, which is attributed primarily to the inherent and acquired radioresistance. Enhancing the radiosensitivity with chemotherapy drugs is a conventional method for locally advanced NPC treatment $[4,5,18]$. However, severe side effects may affect and even interrupt the chemoradiotherapy procedure. A number of studies have demonstrated that EGFR inhibitors can improve the radiosensitivity in many malignant tumors[14-16, 19, 20]. Few studies have focused on the radiosensibility of IH in NPC, which is the aim of the study based on our previous study[17]. 
EGFR expression was presented in $83.5 \%$ of NPC patients, in contrast to $23.3 \%$ of chronic nasopharyngitis patients, with a significant statistical difference. Further analysis showed that EGFR expression was significantly associated with TNM stage and T stage, but not gender, age, tumor differentiation, and lymph node status. In univariate and multivariate Cox proportional regression analysis, two parameters (EGFR expression and TNM stage) and three parameters (EGFR expression, age and TNM stage) were identified as independent prognostic factors for DFS and OS, respectively, while EGFR expression was the common factor. Zhang et al. reported that EGFR expression was $89.5 \%$ in 96 NPC patients and correlated with T stage[21]. Zafar et al. reported 86.35\% of EGFR expression in head and neck squamous cell carcinoma[22].

In addition, EGFR expression is an independent prognostic factor, three-year survival rates were lower in EGFR-positive (75.8\%) patients than in EGFR-negative patients (91.2\%). A meta-analysis including 15 studies and 1,225 NPC patients demonstrated that the pooled HRs for both OS $(2.11[1.23,3.60])$ and DFS $(2.17[1.41,3.35])$ were higher than 2, indicating a strong prognostic value of EGFR[23]. Another meta-analysis including 22 studies produced similar results [8]. Hashmi et al. showed a significant association of EGFR expression with tumor stage and DFS[24]. Inhibiting EGFR expression might be feasible to reverse the radioresistance of NPC cells.

Radioresistant cell lines can be established via cumulative exposure to irradiation[25-27]. In our study, the radioresistant cell line CNE-2R was successfully obtained using a gradient irradiation schedule with accumulated doses of $60 \mathrm{~Gy}$. Compared with CNE-2, CNE-2R cells had stronger ability of proliferation and colony forming, which means a higher radioresistance. There was a higher EGFR expression in CNE-2R cells than CNE-2 cells. When CNE-2R was exposed to $\mathrm{IH}$ (IC20 value, $0.04 \mathrm{mg} / \mathrm{ml}$ ) plus irradiation, EGFR expression and colony-forming ability were reduced. These results demonstrated that $\mathrm{IH}$ improved the radiosensitivity of CNE-2R. Ma et al. evaluated the effect of $\mathrm{IH}$ on radiosensitivity and showed that IH more effectively sensitized colorectal cancer cells (HT29 and HCT116) to radiation[15]. Wang et al. reported $\mathrm{IH}$ can significantly inhibit cell proliferation, redistribute cell cycle, enhance apoptosis and impair DNA damage response of Hela S3 cells following radiation[16].

In conclusion, high EGFR expression is a poor prognostic factor for NPC patients, CNE-2R cells obtained by gradient irradiation are distinguished from the CNE-2 cells in viability, radiosensitivity, and EGFR expression. IH is capable of enhancing the radiosensitivity of CNE-2R. The study provides a new theoretical basis for clinical application of $\mathrm{IH}$ radiosensitization in NPC radiotherapy.

\section{Conclusions}

High EGFR expression was more frequently detected as a poor prognostic factor in NPC patients. Higher EGFR expression and radioresistance were observed in radioresistant cell line CNE-2R, which was reduced by $\mathrm{IH}$. These results provided a new theoretical basis for clinical application of IH radiosensitization in NPC radiotherapy.

\section{Declarations}

\section{Acknowledgments}

We thank all the coordinators and departments for participating in this study, such as other members in our lab.

\section{Funding}

This work was supported by Medical and Health Science and Technology Program of Zhejiang Province (2020RC040) and Taizhou University Research and Breeding Project (2018PY055). 
Availability of data and material

Raw data may be available on request from the corresponding author.

\section{Authors' contributions}

Bo Wu and Hua-cai Xiong contributed equally to this work. All authors read and approved the final manuscript.

\section{Ethics approval and consent to participate}

The Ethics committee of Taizhou Cnetral Hospital approved the study. Written informed consent was obtained from the patients for the participation.

\section{Conflict of publication}

Not applicable

\section{Competing interests}

The authors declare that there are no conflicts of interest.

\section{References}

1. YP C, ATC C, QT L, P B, Y S, and J M, Nasopharyngeal carcinoma. Lancet (London, England), 2019. 394(10192): p. 64-80.

2. Chen L, Hu C, Chen X, Hu G, Cheng Z, Sun Y, et al., Adjuvant chemotherapy in patients with locoregionally advanced nasopharyngeal carcinoma: Long-term results of a phase 3 multicentre randomised controlled trial. Eur. J. Cancer, 2017. 75: p. 150-158.

3. Awm L, Tung SY, Ng WT, Lee V, Rkc N, Hcw C, et al., A multicenter, phase 3, randomized trial of concurrent chemoradiotherapy plus adjuvant chemotherapy versus radiotherapy alone in patients with regionally advanced nasopharyngeal carcinoma: 10-year outcomes for efficacy and toxicity. Cancer, 2017. 123(21).

4. Yu Y, Liang H, Lv X, Ke L, Qiu W, Huang X, et al., Platinum-based concurrent chemotherapy remains the optimal regimen for nasopharyngeal carcinoma: a large institutional-based cohort study from an endemic area. J. Cancer Res. Clin. Oncol., 2018.

5. Hong R, Hsiao C, Ting L, Ko J, Wang C, Chang J, et al., Final results of a randomized phase III trial of induction chemotherapy followed by concurrent chemoradiotherapy versus concurrent chemoradiotherapy alone in patients with stage IVA and IVB nasopharyngeal carcinoma-Taiwan Cooperative Oncology Group (TCOG) 1303 Study. Ann. Oncol., 2018.

6. Sun Y, Li W-F, Chen N-Y, Zhang N, Hu G-Q, Xie F-Y, et al., Induction chemotherapy plus concurrent chemoradiotherapy versus concurrent chemoradiotherapy alone in locoregionally advanced nasopharyngeal carcinoma: a phase 3, multicentre, randomised controlled trial. The Lancet Oncology, 2016. 17(11): p. 1509-1520.

7. $M L$ and E G, Epidermal growth factor receptor (EGFR) involvement in epithelial-derived cancers and its current antibody-based immunotherapies. Cell biology international, 2020.

8. Ooft ML, Braunius WW, Heus P, Stegeman I, van Diest PJ, Grolman W, et al., Prognostic significance of the EGFR pathway in nasopharyngeal carcinoma: a systematic review and meta-analysis. Biomarkers in Medicine, 2015. 9(10): p. 997-1010. 
9. Mitchell R, Luwor R, and Burgess A, Epidermal growth factor receptor: Structure-function informing the design of anticancer therapeutics. Exp. Cell Res., 2018. 371(1): p. 1-19.

10. Huang J, Yuan X, Pang Q, Zhang H, Yu J, Yang B, et al., Radiosensitivity enhancement by combined treatment of nimotuzumab and celecoxib on nasopharyngeal carcinoma cells. Drug Design Development \& Therapy, 2018. 12: p. 2223-2231.

11. Peng H, Tang LL, Liu X, Chen L, Li WF, Mao YP, et al., Anti-EGFR targeted therapy delivered before versus during radiotherapy in locoregionally advanced nasopharyngeal carcinoma: a big-data, intelligence platform-based analysis. BMC Cancer, 2018. 18(1): p. 323.

12. You R, Sun R, Hua YJ, Li CF, Li JB, Zou X, et al., Cetuximab or nimotuzumab plus intensity-modulated radiotherapy versus cisplatin plus intensity-modulated radiotherapy for stage II-IVb nasopharyngeal carcinoma. International Journal of Cancer, 2017. 141(6): p. 1265.

13. Lin M, You R, Liu YP, Zhang YN, Zhang HJ, Zou X, et al., Beneficial effects of anti-EGFR agents, Cetuximab or Nimotuzumab, in combination with concurrent chemoradiotherapy in advanced nasopharyngeal carcinoma. Oral Oncol, 2018. 80: p. 1-8.

14. Zhang S, Fu Y, Wang D, and Wang J, Icotinib enhances lung cancer cell radiosensitivity in vitro and in vivo by inhibiting MAPK/ERK and AKT activation. Clinical \& Experimental Pharmacology \& Physiology, 2018.

15. $\mathrm{Ma} \mathrm{H}, \mathrm{Bi}$ J, Liu T, Ke Y, Zhang S, and Zhang T, Icotinib hydrochloride enhances the effect of radiotherapy by affecting DNA repair in colorectal cancer cells. Oncology Reports, 2015. 33(3): p. 1161-1170.

16. Wang X, Gu Y, Liu H, Shi L, and Sun X, Icotinib hydrochloride enhances chemo- and radiosensitivity by inhibiting EGFR signaling and attenuating RAD51 expression and function in Hela S3 cells. Onco Targets Ther, 2018. Volume 11: p. 1245-1258.

17. Hu W, Wang W, Yang P, Zhou C, Yang W, Wu B, et al., Phase I study of icotinib, an EGFR tyrosine kinase inhibitor combined with IMRT in nasopharyngeal carcinoma. Int J Clin Exp Med, 2015. 8(9): p. 15675-15683.

18. Chen Y, Tang L, Yang Q, Poh S, Hui E, Chan A, et al., Induction Chemotherapy plus Concurrent Chemoradiotherapy in Endemic Nasopharyngeal Carcinoma: Individual Patient Data Pooled Analysis of Four Randomized Trials. Clin. Cancer Res., 2018. 24(8): p. 1824-1833.

19. Y M and D S, Lapatinib, a Dual Inhibitor of Epidermal Growth Factor Receptor (EGFR) and HER-2, Enhances Radiosensitivity in Mouse Bladder Tumor Line-2 (MBT-2) Cells In Vitro and In Vivo. Medical science monitor : international medical journal of experimental and clinical research, 2018. 24: p. 5811-5819.

20. N W, L W, X M, J W, L Z, C L, et al., Osimertinib (AZD9291) increases radio-sensitivity in EGFR T790M non-small cell lung cancer. Oncology reports, 2019. 41(1): p. 77-86.

21. Zhang P, Wu SK, Wang Y, Fan ZX, Li CR, Feng M, et al., p53, MDM2, elF4E and EGFR expression in nasopharyngeal carcinoma and their correlation with clinicopathological characteristics and prognosis: A retrospective study. Oncol Lett, 2015. 9(1): p. 113-118.

22. M Z, SN H, MJ F, R A, and SS A, Immunohistochemical Expression of Epidermal Growth Factor Receptor in Head and Neck Squamous Cell Carcinoma. Journal of the College of Physicians and Surgeons-Pakistan : JCPSP, 2017. 27(4): p. 209-212.

23. Ma X, Huang J, Wu X, Li X, Zhang J, Xue L, et al., Epidermal growth factor receptor could play a prognostic role to predict the outcome of nasopharyngeal carcinoma: A meta-analysis. Cancer Biomark, 2014. 14(4): p. $267-77$.

24. AA H, ZF H, S A, M I, EY K, S N, et al., Immunohistochemical expression of epidermal growth factor receptor (EGFR) in South Asian head and neck squamous cell carcinoma: association with various risk factors and clinicopathologic and prognostic parameters. World journal of surgical oncology, 2018. 16(1): p. 118.

Page $11 / 15$ 
25. Luo M, Ding L, Li Q, and Yao H, miR-668 enhances the radioresistance of human breast cancer cell by targeting IKBa. Breast Cancer, 2017. 24(5): p. 1-10.

26. Wang Y, He J, Zhang S, and Yang Q, Intracellular calcium promotes radioresistance of non-small cell lung cancer A549 cells through activating Akt signaling. Tumour Biol, 2017. 39(3): p. 1010428317695970.

27. V T, A P, MN Z, M S, A B, B G, et al., Mechanisms of different response to ionizing irradiation in isogenic head and neck cancer cell lines. Radiation oncology (London, England), 2019. 14(1): p. 214.

\section{Figures}

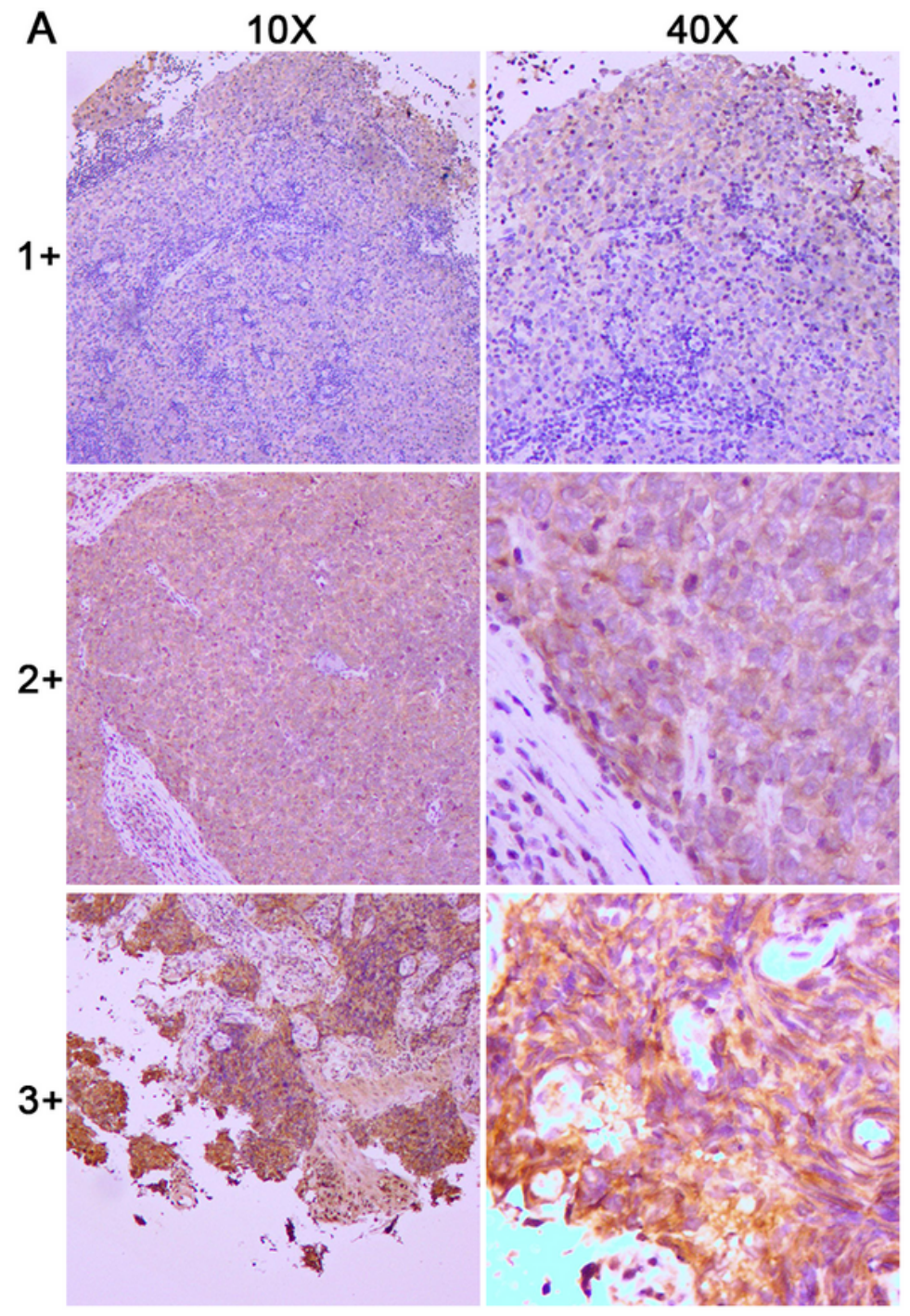

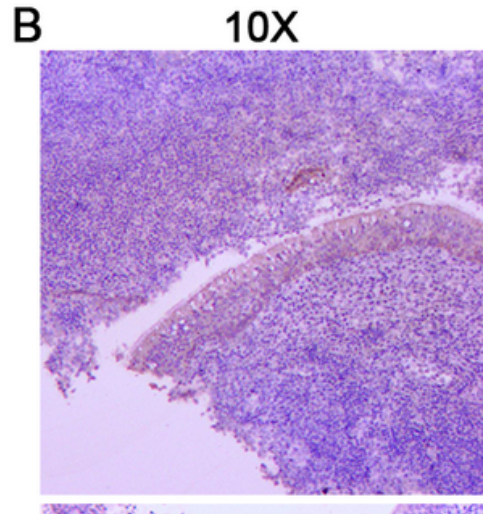
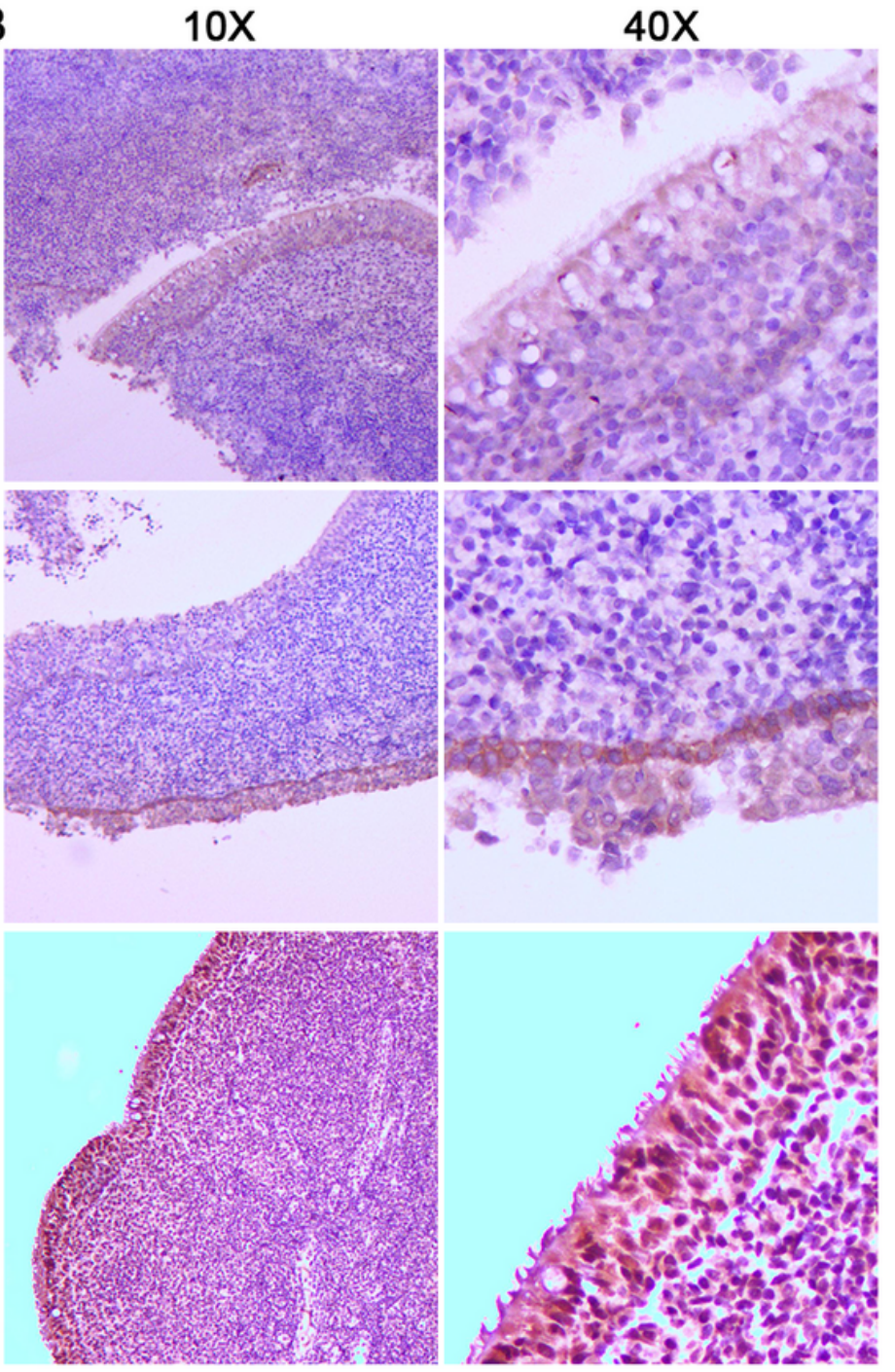

\section{Figure 1}

Different immunohistochemical staining intensity $(1+, 2+, 3+)$ of EGFR under 10X and 40X magnification. (A) Primary NPC lesions; (B) chronic nasopharyngitis lesions. 

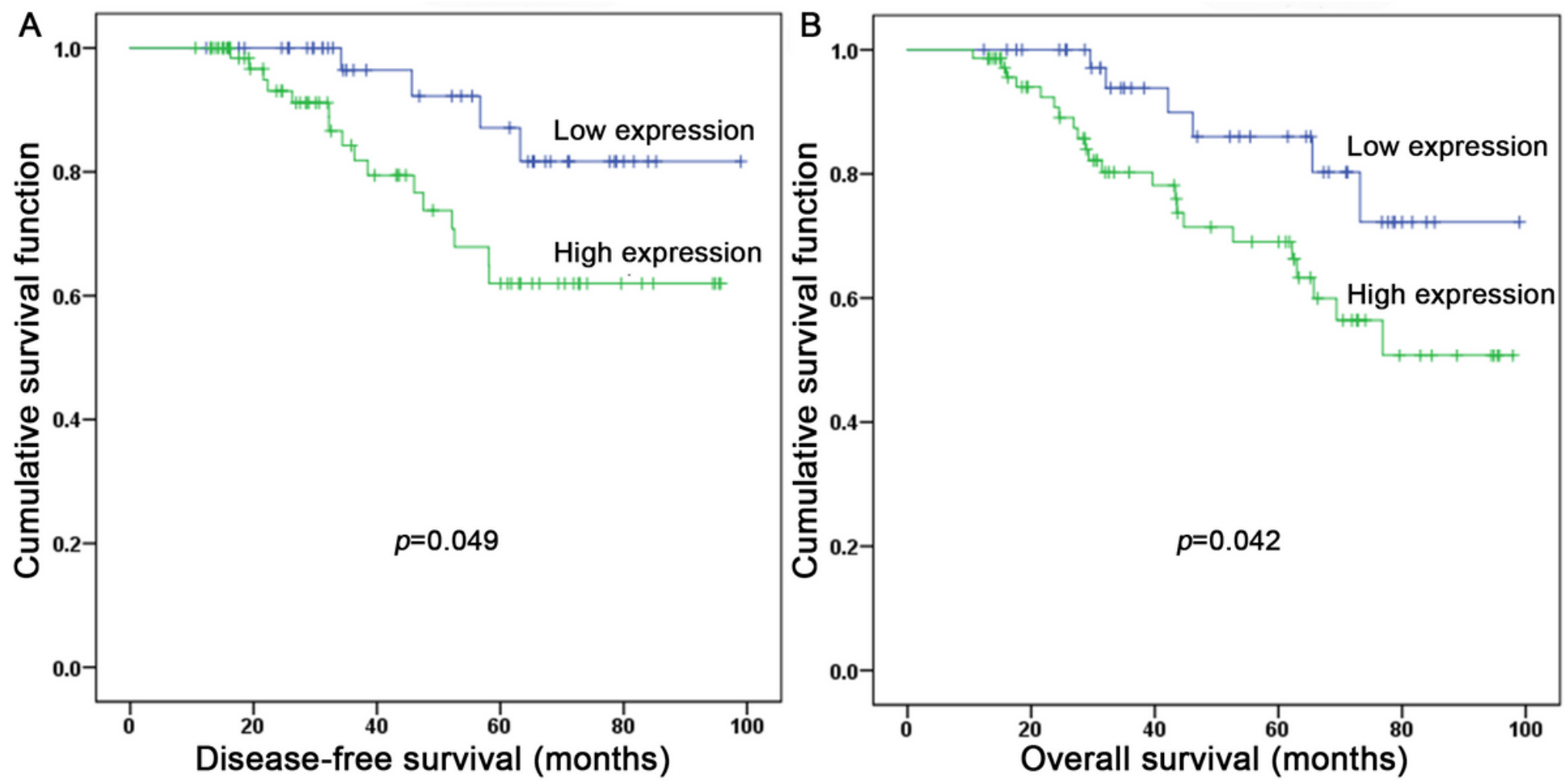

Figure 2

Kaplan-Meier survival analysis for NPC patients: (A) comparison of disease-free survival (DFS) between high and low EGFR expression $(p=0.049)$. (B) Comparison of overall survival $(O S)$ between high and low EGFR expression $(p=$ 0.042). 
A

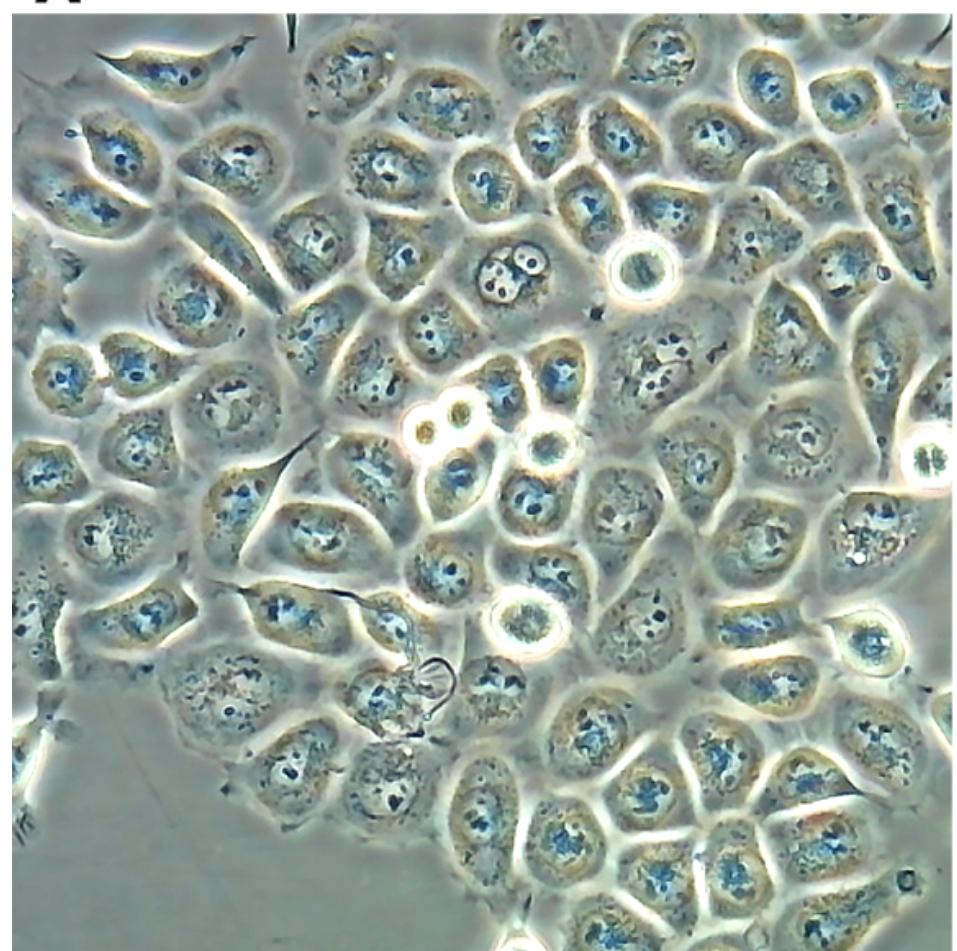

C

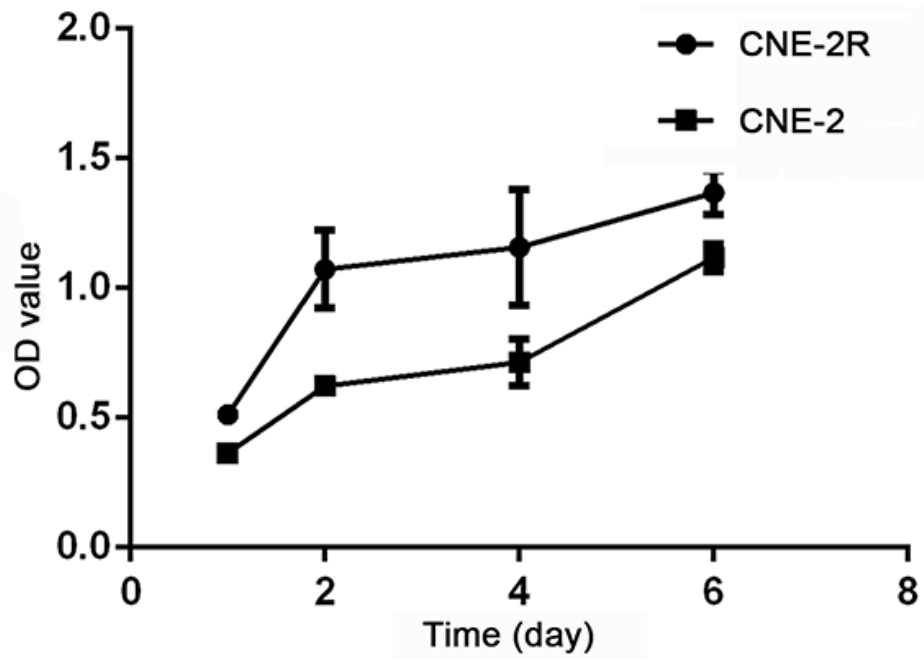

B

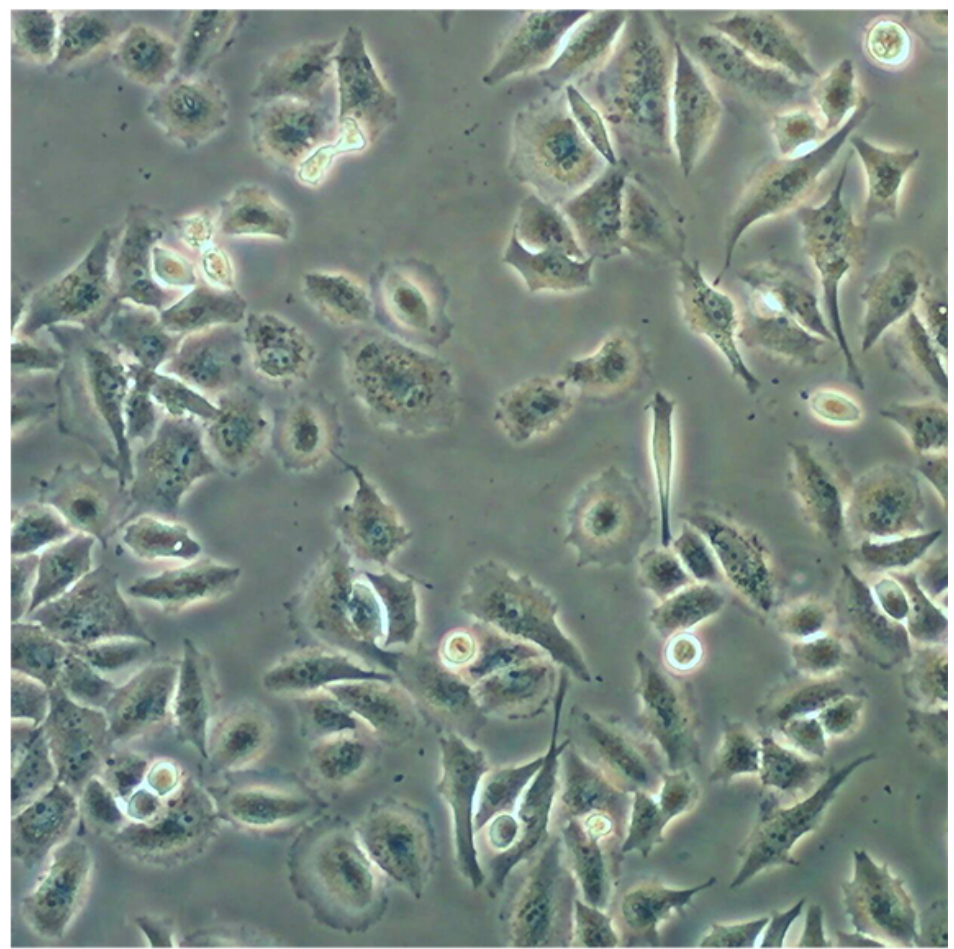

D

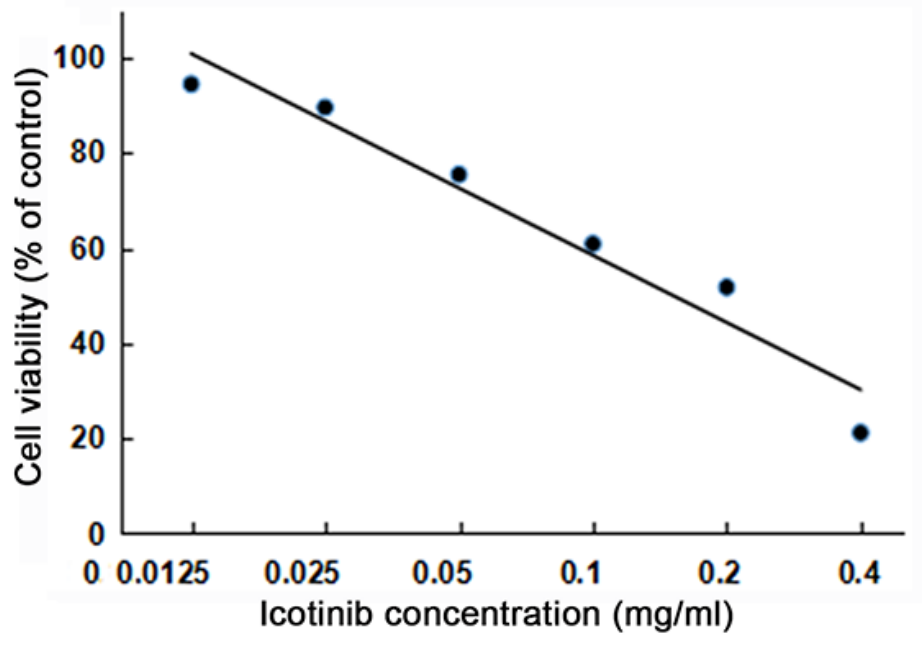

Figure 3

(A) CNE-2 cells with a multilateral manner; (B) CNE-2R cells with the shape of spindle or fusiform; (C) cell viability at different time points was determined by MTT assay; (D) cell viability of CNE-2 under different icotinib concentration. 


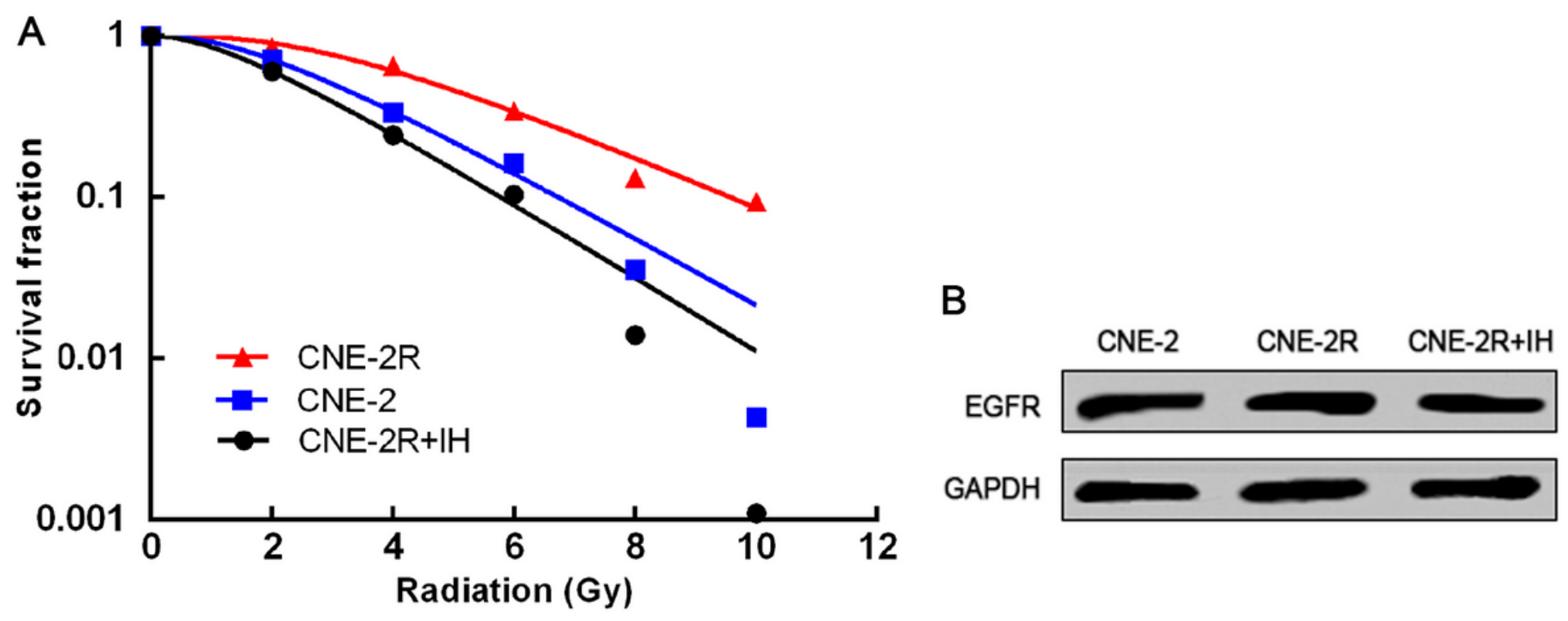

Figure 4

(A) The three cohorts were exposed to different dose and continuously incubated until macroscopic colony ( $>50$ cells per colony) appeared. Survival fraction curve was conducted; (B) expression level of EGFR protein in CNE-2/2R cells was detected by western blot for the three treatment groups. 